\title{
Avaliação de risco ambiental por contaminação metálica e material orgânico em sedimentos da bacia do Rio Aurá, Região Metropolitana de Belém - PA
}

\author{
Gilmar W. SIQUEIRA, Fabio APRILE, ${ }^{2,}$
}

\begin{abstract}
RESUMO
A bacia do Rio Aurá está situada na região metropolitana de Belém, entre os municípios de Belém e Ananindeua, onde a taxa populacional tem aumentado sem qualquer medida de controle social ou ambiental. A regiáo é intensamente explorada, sendo que os principais problemas ambientais são o desmatamento, erosão, inundação, poluição e contaminação das águas, especialmente por metais pesados e compostos orgânicos. O comportamento geoquímico dos elementos $\mathrm{Al}, \mathrm{Fe}, \mathrm{Mn}, \mathrm{Cr}, \mathrm{Ni}$ e Cu e os teores de compostos orgânicos foram avaliados em 30 pontos de amostragem no período entre 2008 e 2010 nos sedimentos fluviais. $\mathrm{O}$ aterro sanitário não controlado localizado nas proximidades da bacia do Rio Aurá é responsável, em parte, pela contaminação dos sedimentos. O estresse ambiental é resultado das atividades antrópicas locais, que contribuem no transporte de material clástico contendo metais para o rio. As variáveis estudadas foram classificadas segundo mecanismos de transporte e fonte (autóctone ou alóctone). Os resultados demonstraram que a principal contribuição de íons $\mathrm{Al}$ e Fe foi o aterro sanitário; Mn e Ni vieram principalmente dos solos adjacentes; Cr foi modificado (III/VI) por processo alobioquímico e Cu por processo bioinduzido.
\end{abstract}

PALAVRAS-CHAVE : metais pesados; saneamento; vulnerabilidade; geoquímica; Amazônia

\section{Evaluation of environmental risk by metallic contamination and organic compounds in sediments of the Aurá River basin, Belém, Pará - Brazil}

\section{ABSTRACT}

The Aurá River basin is situated in the Belém Metropolitan region, between the municipalities of Belém and Ananindeua, where the rate of population growth has increased without any social and environmental control. The region is intensely exploited and the more frequent environmental problems are deforestation, erosion, flooding, water pollution and contamination, especially by heavy metals and organic compounds (OC). Geochemistry behavior ( $\mathrm{Al}, \mathrm{Fe}, \mathrm{Mn}, \mathrm{Cr}, \mathrm{Ni}$ and $\mathrm{Cu}$ ) and $\mathrm{OC}$ levels were determined in the 30 sampling sites between 2008 and 2010 in the bottom sediments of the river. There is an uncontrolled sanitary landfill situated at the north of the Aurá River responsible, in part, by the metallic contamination of the sediments. The environmental stress is classic in the region, and it has resulted from anthropic activities, which has transported unconsolidated material associated to metals to the Aurá. The variables studied were classified on the transport mechanisms and sources (allochthonous and/or autochthonous). The results showed that the main contribution of ions $\mathrm{Al}$ and $\mathrm{Fe}$ was the sanitary landfill; $\mathrm{Mn}$ and $\mathrm{Ni}$ was the adjacent soils; $\mathrm{Cr}$ was modified (III/VI) by the allobiochemistry, and $\mathrm{Cu}$ by bio-induced processes.

KEYWORDS: heavy metals; sanitation; vulnerability; geochemistry; Amazonia

\footnotetext{
1 Departamento de Química, Universidade Federal do Pará. Av. Augusto Corrêa n. 1, Campus Universitário do Guamá, 66075-100 Belém, PA, Brasil. Fone: (91)32017910. E-mail: gilmar@ufpa.br

${ }^{2}$ Laboratório de Estudos de Ecossistemas Amazônicos, Universidade Federal do Oeste do Pará, Av. Marechal Rondon s/n Caranazal, 68040-070 Santarém, PA, Brasil. Fone: (93)30649066. E-mail: aprilefm@hotmail.com.

* Correspondence author.
} 


\section{INTRODUÇÃO}

As várzeas e os rios da região Amazônica são ambientes muito sensíveis à poluição ambiental, especialmente as bacias próximas da zona costeira, cujas águas são movimentadas com menor energia pelos fluxos de marés, fazendo com que esses ecossistemas se tornem acumuladores naturais de resíduos de origem inorgânica e/ou orgânica. No contexto da geomorfologia local, a forma sinuosa dos canais, associada à imensa carga de material sedimentar transportada pelo pulso de inundação, contribui ainda mais para o processo de acumulação residual na região.

A Região Metropolitana de Belém (RMB) é cortada por rios, canais e igarapés, além de apresentar lagos artificiais de diversificados tamanhos e formas. Nesse imenso mosaico, composto pelos ecossistemas aquáticos, há uma constante pressão antrópica devido à ocupação irregular das imediações das áreas preservadas, acarretando poluição e contaminação dos corpos de águas superficiais. Dentre as pressóes ao meio ambiente, merecem destaque dois fatores: 1) o aterro sanitário do Aurá, considerado descontrolado por Ferreira e Costa (2006), entre outros motivos pelas diversas irregularidades na ocupaçáo e operação do terreno, descarte de lixo a céu aberto, e ausência de controle de atividades e de pessoas no seu entorno; e 2) presença de inúmeros esgotos clandestinos decorrentes da falta de um programa de saneamento adequado às comunidades da periferia da RMB. Os esgotos domésticos contribuem com elevada carga de material orgânico (especialmente $\mathrm{C}, \mathrm{N}$ e $\mathrm{P}$ ), que por sua vez contribui para a eutrofização dos riachos (igarapés) urbanos. Além do impacto no meio ambiente natural que a pluma de chorume causa, o risco potencial de contaminação é agravado com a utilização dessas águas para o consumo pelas populaçóes locais e, para o abastecimento público pelos sistemas de captação de água potável da regiáo.

Aguiar (2000) estudando os efeitos da poluição ambiental de canais de drenagem na RMB, especialmente na bacia do Rio Tucunduba, uma região bastante similar à área de estudo deste trabalho, demonstrou que aproximadamente 46\% dos entrevistados já haviam contraído algum tipo de doença gastrintestinal, genericamente identificada como diarréia; $24 \%$ dos entrevistados contraído esquistossomose e/ou leptospirose; $19 \%$ a verminose; $38 \%$ a cólera e $12 \%$ a hepatite infecciosa.

A bacia do Rio Aurá é a terceira maior em extensão da RMB, e exerce forte influência sobre os mananciais de captação de água para abastecimento público da cidade de Belém (Mananciais Água Preta e Bolonha; Figura 1), sendo de extrema importância identificar os possíveis impactos ambientais presentes na área de estudo, a fim de subsidiar políticas públicas para a preservação e conservação da bacia hidrográfica.
Os objetivos deste trabalho foram: 1) fazer uma avaliação da qualidade ambiental da bacia do Rio Aurá (RMB), a partir de uma análise da concentração e distribuição de elementos metálicos (Al, Fe, Mn, Cr, Ni e Cu) e cargas orgânicas nos sedimentos desta; 2) identificar o gradiente de distribuição espaço-temporal e o fluxo dos íons metálicos entre os compartimentos água e sedimento; e 3) classificar os materiais sedimentares a partir da caracterização do transporte e razão dos nutrientes.

\section{MATERIAL E MÉTODOS}

A RMB está situada em um embasamento geológico de cobertura Cenozóica, sobre o mais baixo nível dos terrenos quaternários da Amazônia, distando $120 \mathrm{~km}$ do oceano Atlântico e assentada sobre terraços resultantes do entalhamento processado pela rede de drenagem local. O resultado é uma cobertura sedimentar não muito resistente e, portanto, facilmente erodível. O perfil geográfico, similar ao de outras regióes da Amazônia, apresenta gradaçôes de relevo variando entre igapós, várzeas e terra-firme. As margens da bacia do Rio Aurá, especialmente no médio e baixo curso, assim como as do Rio Guamá, são formadas por planícies de acumulação fluvial holo-pleistocênica.

Segundo a classificação de Köppen, o clima da RMB se enquadra na categoria "equatorial úmido" do tipo 'Afi', com precipitação anual média de $2000 \mathrm{~mm}$ e temperatura média de $35^{\circ} \mathrm{C}$ (Ferreira e Costa 2006). As chuvas se estendem de dezembro a maio, enquanto que o período seco ou menos chuvoso vai de junho a novembro. Com relação ao tipo de solo, predominam na RMB o Latossolo Amarelo, seguido do Concrecionário Laterítico, Glay pouco húmico, Podzol Hidromórfico e Areias Quartzosas (Embrapa 1999).

O Rio Aurá está localizado na extremidade sudeste da cidade de Belém, e forma uma micro-bacia, pertencente à bacia do Rio Guamá, com drenagens de pequeno porte e pouca extensão, como é o caso dos igarapés Santo Antônio do Aurá, Pescada, Juvêncio, Jaruca e Santana do Aurá. A Oeste da micro-bacia, cerca de $1.400 \mathrm{~m}$ de distância, estão localizados os mananciais dos lagos Bolonha e Água Preta (Figura 1), que abastecem de água a RMB, e aproximadamente a mesma distância no rumo Norte, acima do ponto $1 \mathrm{da}$ área monitorada, encontra-se instalado um aterro sanitário em uso. A bacia do Rio Aurá possui uma extensão total de aproximadamente $10.400 \mathrm{~m}$ distribuídos pelos principais corpos de água da seguinte forma: Rio Aurá com $\cong 6800 \mathrm{~m}$; igarapé Santo Antonio do Aurá com $\cong 2000 \mathrm{~m}$, e igarapé Santana do Aurá com $\cong 1600 \mathrm{~m}$.

Foram selecionados 30 pontos ao longo da bacia do Rio Aurá entre as isóbatas de 0,5 a $8,5 \mathrm{~m}$. Em cada ponto foi amostrado $1 \mathrm{~kg}$ de sedimento de fundo com amostrador Van-Veen, e de cada amostra foi retirada uma subamostra 


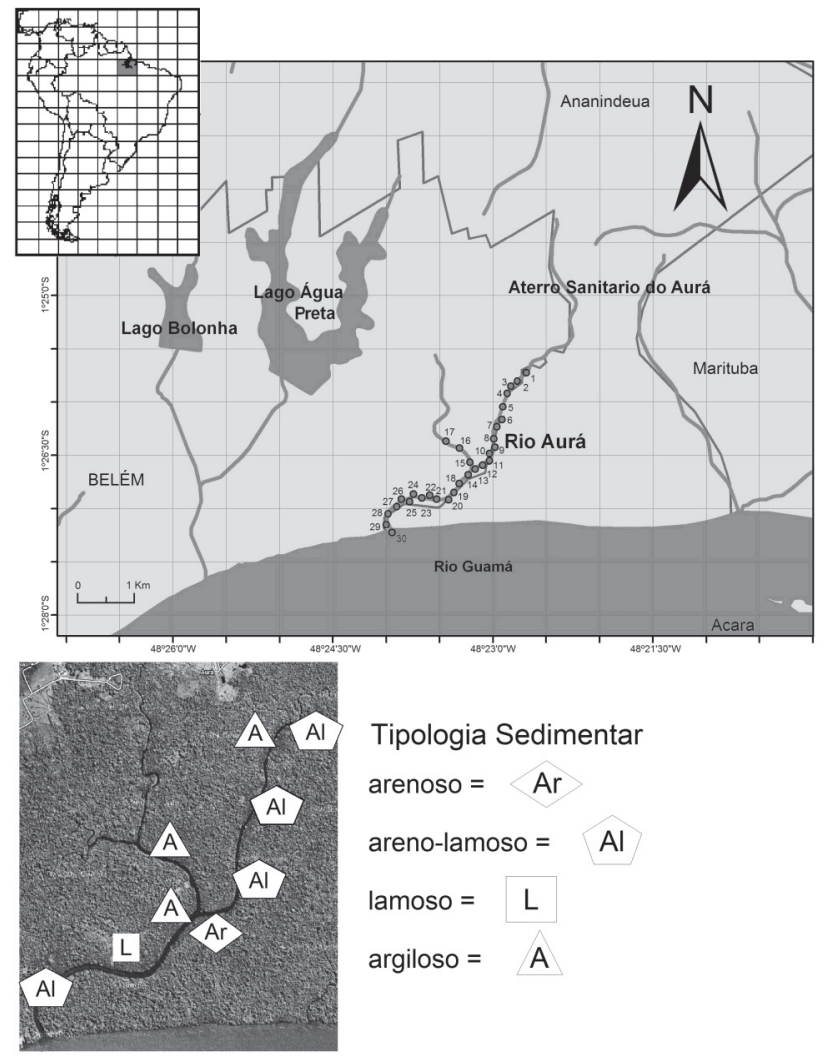

Figura 1- Mapa da área de estudo na bacia do Rio Aurá, RMB - Pará, com a localização do aterro sanitário e dos lagos usados na captação de água para abastecimento público, e tipologia sedimentar da bacia.

com espátula de polietileno e acondicionada em câmara fria a aproximadamente $-20^{\circ} \mathrm{C}$. As coletas se realizaram sempre durante os períodos de baixa pluviosidade: 09/2008, 09/2009 e 10/2010. No campo foram realizadas medidas de temperatura $\left({ }^{\circ} \mathrm{C}\right)$, oxigênio dissolvido $\left(\mathrm{mg} \mathrm{L}^{-1}\right)$ e teor de saturação do oxigênio (\%), através de sonda multiparâmetro YSI modelo 550A de resolução expandida $0,01 \mathrm{mg} / 1$ - 0,1\% $0,1^{\circ} \mathrm{C}$, compensação automática de temperatura e salinidade, calibração automática em um ponto (ar), Cole-Parmer/EUA. No laboratório de Química da Faculdade de Química da Universidade Federal do Pará - UFPA procedeu-se o prétratamento das amostras, seguindo o protocolo: 1) secagem em estufa de circulação de ar $40 \pm 5^{\circ} \mathrm{C}$ por 48 horas; 2) desagregação, homogeneização e quarteamento das amostras; e 3) peneiramento e separaçáo da fração fina $(<0,063 \mathrm{~mm})$ destinada a análise de metais.

\section{Macronutrientes orgânicos}

Os macronutrientes foram assim analisados: 1) Carbono orgânico $\left(\mathrm{C}_{\text {org }}\right)$ utilizando-se o método dicromatométrico em meio sulfúrico (Byers et al. 1978; APHA 2005); 2) Nitrogênio orgânico $\left(\mathrm{N}_{\text {org }}\right)$ pela técnica de Kjeldahl, que converte todas as formas nitrogenadas orgânicas em amônia, na presença da mistura $\left[\mathrm{H}_{2} \mathrm{SO}_{4}-\mathrm{NaOH}-\mathrm{H}_{3} \mathrm{BO}_{3}\right]$ seguida de titulação por volumetria de neutralizaçáo (Aprile e Bianchini Jr 2003). A partir dos resultados de $\mathrm{C}_{\text {org }}$ e $\mathrm{N}_{\text {org }}$ foram calculados os valores para a razão $\mathrm{C} / \mathrm{N}$. Para a obtenção dos teores de matéria orgânica $(\mathrm{MO})$ recorreu-se à relação $\mathrm{MO}: \mathrm{C}_{\mathrm{org}}$ apresentada na Equação 1:

$$
\% \text { M.O. }=\% C_{\text {org }} \times F
$$

Onde, $F$ que é igual a 1,724 é o fator de proporcionalidade entre a matéria orgânica e $\mathrm{C}_{\text {org }}$ nos meios naturais.

\section{Análise dos íons metálicos}

A digestão ácida das subamostras para análise de metais consistiu em acondicionar $1 \pm 0,001 \mathrm{~g}$ da fração fina $(<0,063$ $\mathrm{mm}$ ) seca em béquer de teflon de $50 \mathrm{~mL}$ com mistura ácida extra-forte $\left[5 \mathrm{~mL}\right.$ de $\mathrm{HNO}_{3}+2 \mathrm{~mL}$ de $\mathrm{HClO}_{4}+20 \mathrm{~mL}$ de $\mathrm{HF}$ e e levar a chapa aquecedora a $100^{\circ} \mathrm{C}$ por seis horas. Após a primeira etapa de digestâo, adicionaram-se $10 \mathrm{~mL}$ de $\mathrm{HCl} 6 \mathrm{M}$ as amostras e fez-se um aquecimento brando para dissolução dos sais. As soluçóes finais foram acondicionadas a balóes de $100 \mathrm{~mL}$ e o volume final completado com água deionizada, para posterior análise por espectrometria de absorção atômica com chama (EAA), no Laboratório de Análise via Absorção Atômica do Museu Paraense Emílio Goeldi - MPEG, segundo procedimento de número 3500-B descrito por APHA (2005) para digestão total. Todas as análises foram feitas em triplicata. Os resultados obtidos na extração total foram comparados com os valores de referência apresentados por Bowen (1979) para folhelho geológico médio padrão. Para uma análise criteriosa da qualidade ambiental foi utilizado como base de comparação os valores citados pela Agencia de Proteção Ambiental Americana - EPA (Thomas 1987) para sedimentos poluídos e não poluídos.

Para avaliar as mudanças nos teores dos íons metálicos estudados nas amostras de sedimentos coletados foram calculados os fatores de enriquecimento (FE), utilizando-se da equação descrita por Woitke et al. (2003) e Selvaraj et al. (2004):

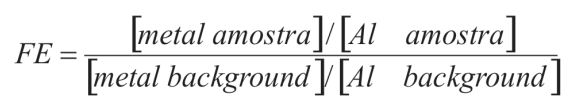

Onde, o fator de referência ou normalizador é usualmente o teor médio de $\mathrm{Al} \mathrm{no} \mathrm{ambiente} \mathrm{de} \mathrm{estudo,} \mathrm{bem} \mathrm{como} \mathrm{na} \mathrm{área}$ de referência natural (background).

Os resultados foram tratados estatisticamente utilizando-se da Análise Multivariada e Análise de Componentes Principais (PCA) para: a) examinar o grau de afinidade entre os elementos metálicos e os componentes orgânicos; b) definir o padrão de distribuição das variáveis dentro da bacia; c) identificar sua correlação com as atividades antrópicas existentes, e d) classificar os materiais sedimentares a partir dos padróes de transporte dos mesmos. 


\section{RESULTADOS E DISCUSSÃO}

Os resultados dos teores de íons metálicos (Al, Fe, Mn, $\mathrm{Cr}$, $\mathrm{Ni}$ e $\mathrm{Cu}$ ) com os valores médio, máximo e mínimo são apresentados na Figura 2, para as amostras de sedimentos de fundo da bacia do Rio Aurá. $\mathrm{O} \mathrm{Al}$ apresentou teores que variaram entre $2,61 \%$ e 6,07\% e média de $4,41 \pm 0,66 \%$. Esses valores ficaram abaixo do valor de referência para folhelho médio padrão de 8,8\% para Al citado por Bowen (1979). Destaca-se também que os teores de $\mathrm{Al}$ em todos os pontos estudados ficaram abaixo do valor de referência para crosta da Terra, que é de 7,96\% segundo Wedepohl (1995). Em princípio, os resultados obtidos para $\mathrm{Al}$ podem estar refletindo o quadro litológico da regiáo, visto que este elemento metálico pode apresentar um padrão conservativo, e por esta razáo é usado como valor de referência ou normalizador na determinação do fator de enriquecimento (Equação 2). Analisando a distribuição espaço-temporal do $\mathrm{Al}$ ao longo da bacia do Aurá, nota-se que as maiores concentraçóes deste, em ordem decrescente, foram encontradas nos pontos 14, 18, 6 e 22 (Figura 2A), assim como a tendência de decréscimo dos teores mais a jusante do rio, na direção da confluência do Aurá com o Rio Guamá. Estudos realizados por Mendes e Berredo (2003) no compartimento sedimento de fundo do Rio São Joaquim, um dos afluentes da bacia hidrográfica do Una (Pará), e por Siqueira et al. (2005) no canal do Una, revelaram teores médios de 2,45\% e 2,22\%, respectivamente. Comparando-se tais resultados com os obtidos neste trabalho, pode-se aventar um enriquecimento por $\mathrm{Al}$ nos sedimentos do Rio Aurá, visto esse ser pouco móvel em ecossistemas aquáticos (Yun et al. 2000; Selvaraj et al. 2004), e geralmente enriquecido em sedimentos lixiviados.

$\mathrm{O} \mathrm{Fe}$ total apresentou concentraçóes que variaram de $1,54 \%$ a $3,46 \%$, com média de $2,46 \pm 0,32 \%$. Esses valores ficaram abaixo do teor citado para folhelho médio padrão de 4,8\% para ferro descrito por Bowen (1979). No aspecto espaço-temporal destacaram-se com as maiores concentraçóes e em ordem decrescente os pontos 18, 14, 12 e 22 (Figura 2B). Os pontos 14 e 18 estão situados imediatamente após a conexão do Rio Aurá com o igarapé Santo Antonio (Figura 1). Este, por sua vez, atravessa uma região que começa a dar sinais de expansão urbana desordenada, com construçóes irregulares sem qualquer sistema de coleta de esgotos, representando assim um aporte de esgotos não tratados associados aos resíduos da atividade agrícola de subsistência da comunidade ribeirinha.
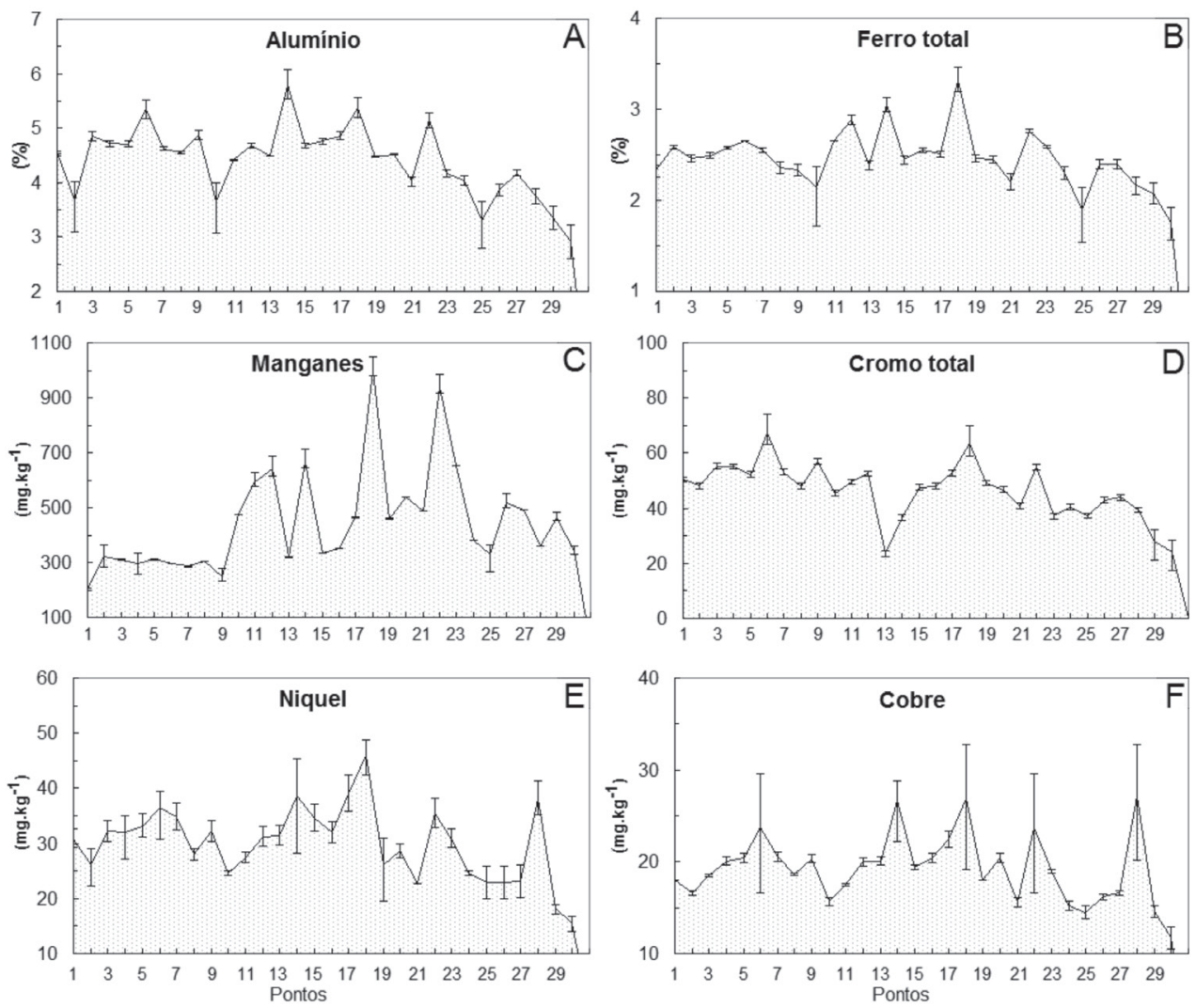

Figura 2- Gradiente de distribuição espaço-temporal dos metais (Al, Fe, Mn, Cr, Ni e Cu) nos sedimentos do Rio Aurá, no período entre 2008 e 2010. 
Seguindo a mesma tendência apresentada pelo elemento $\mathrm{Al}$ houve uma reduçáo da concentraçáo de Fe total nos sedimentos de fundo a jusante da bacia, especialmente nos pontos $29 \mathrm{e}$ 30. Ambos os íons metálicos, cujo estado de oxidação é +3 $\left(\mathrm{Fe}^{3+}\right.$ e $\left.\mathrm{Al}^{3+}\right)$, tem grande afinidade por compostos aniônicos (eletronegatividade $\mathrm{Fe}=1,83$ e $\mathrm{Al}=1,61$ ), apresentando boa complexaçáo com os argilominerais e matéria orgânica. Não há um padrão definido para $\mathrm{Fe}$ e $\mathrm{Al}$ no que se refere à abundância em águas e sedimentos de fundo continentais, sendo que sua concentraçáo está associada a fatores físicos e químicos como: $\mathrm{pH}$ do meio, potencial redox, concentração de $\mathrm{O}_{2}$ dissolvido, presença de elementos carbonatos e matéria orgânica, entre outros.

Comparando os resultados deste trabalho com outros similares realizados na RMB, nota-se que as concentraçôes de Fe total encontradas na bacia do Aurá foram ligeiramente mais elevadas. Mendes e Berredo (2003) encontraram valor médio de 1,31\% para o Fe, enquanto que Siqueira et al. (2005) obtiveram uma média ligeiramente mais alta no canal do Rio Una, em torno de $1,81 \%$. Segundo a EPA, as concentraçóes de Fe entre $1,7 \%$ a 2,5\% no sedimento o classificariam como moderadamente poluído, o que de certa maneira foi verificado na maioria dos pontos de coletas, e acima disso altamente poluídos, como detectados nos pontos 14 e 18 .

Os metais tendem a precipitar para o sedimento quando as condiçóes físicas, químicas e físico-químicas se alteram na coluna de água. Neste caso, é possível que uma parte do elemento Fe determinado possa estar associado aos argilominerais, bastante predominantes nas águas brancas ou barrentas, o que facilitaria sua precipitação. A hematita $\left[\mathrm{Fe}_{2} \mathrm{O}_{3}\right]$ é um dos minerais mais comuns em sedimentos de fundo na regiáo, enquanto que a ocorrência da limonita $\left[\mathrm{Fe}_{2} \mathrm{O}_{3} \mathrm{H}_{2} \mathrm{O}\right]$ aparece como resultado da alteração da hematita pela formação do óxido de ferro hidratado.

Os valores de $\mathrm{Mn}$ total oscilaram entre $204,9 \mathrm{mg} \mathrm{kg}^{-1}$ a $979,6 \mathrm{mg} \mathrm{kg}^{-1}$, com média de 441,2 $\pm 182,5 \mathrm{mg} \mathrm{kg}^{-1}$. Observou-se que a maioria dos pontos de coletas os teores encontrados para $\mathrm{Mn}$ ficaram abaixo do valor de $850 \mathrm{mg} \mathrm{kg}^{-1}$ citado para folhelho médio padraao, segundo Bowen (1979). Da mesma forma que o Fe, o Mn também permaneceu acima dos valores obtidos por outros autores na regiáo. $\mathrm{O}$ teor médio determinado de Mn por Siqueira et al. (2005) foi de 54,51 $\mathrm{mg} \mathrm{kg}{ }^{-1} \mathrm{em}$ sedimentos do canal do Una, enquanto Mendes e Berredo (2003) obtiveram média de $37,56 \mathrm{mg} \mathrm{kg}^{-1}$ no sedimento do Rio São Joaquim. Sobre a determinação do grau de poluição do sedimento, com base nos teores de Mn, a EPA considera não poluído o sedimento com teor inferior a $300 \mathrm{mg}$ $\mathrm{kg}^{-1}$, moderadamente poluído o sedimento com concentração entre $300 \mathrm{mg} \mathrm{kg}^{-1}$ e $500 \mathrm{mg} \mathrm{kg}^{-1}$ e altamente poluído o sedimento com teores acima de $500 \mathrm{mg} \mathrm{kg}^{-1}$. Tomando por base esse critério, destacaram-se os pontos 11, 12, 14, 18, 22 e 23, os quais teriam seus sedimentos de fundo enquadrados como altamente poluídos (valores $>500 \mathrm{mg} \mathrm{kg}^{-1}$ ). Na Figura 2C é apresentado o gradiente de distribuiçáo do $\mathrm{Mn}$ ao longo do Rio Aurá. Em geral, observou-se que há uma inversão na tendência de distribuição encontrada nos teores de $\mathrm{Mn}$ em relação aos outros íons metálicos estudados, sendo que para o Mn ocorreu uma diminuiçáo das suas concentraçóes em direção a montante da bacia, muito embora, essa diminuição signifique elevados teores em relação aos encontrados por outros autores na região, como já foi mencionado. De certa forma, o $\mathrm{Mn}$ encontra-se, muitas vezes, incorporado a determinados minerais como a biotita $\left[\mathrm{K}(\mathrm{Mg}, \mathrm{Fe})_{3}\left(\mathrm{Al}, \mathrm{Si}_{3} \mathrm{O}_{10}\right)\right.$ $\left.(\mathrm{OH})_{2}\right]$ e honrblenda $\left[(\mathrm{Ca}, \mathrm{Na})_{2-3}(\mathrm{Mg}, \mathrm{Fe}, \mathrm{Al})_{5} \mathrm{Si}_{6}(\mathrm{Si}, \mathrm{Al})_{2} \mathrm{O}_{22}(\right.$ $\mathrm{OH})_{2}$, nas posiçôes de outros elementos de mesma carga e de tamanho semelhante por exemplo, o Fe.

Os teores de Cr oscilaram ente 22,60 mg kg-1 a 63,20 mg kg${ }^{-1}$, com média de 45,39 $\pm 9,39 \mathrm{mg} \mathrm{kg}^{-1}$ para todo o sistema fluvial estudado. Observou-se que em todos os sítios os teores obtidos para Cr ficaram abaixo do valor de $90 \mathrm{mg}$ $\mathrm{kg}^{-1}$ citado para folhelho médio padráo segundo Bowen (1979). Na comparaçâo com sedimentos de ecossistemas lóticos similares, a concentração media obtida por Siqueira et al. (2005) nos sedimentos do canal do Una foi de 50,44 $\mathrm{mg} \mathrm{kg}^{-1} \mathrm{de} \mathrm{Cr}$, enquanto que o teor médio determinando por Mendes e Berredo (2003) foi de 48,80 $\mathrm{mg} \mathrm{kg}^{-1}$. Neste caso, observou-se certa similaridade de correlação do teor médio de Cr obtido nesta pesquisa, com os teores médios obtidos pelos últimos autores $\left(R^{2}=0,655\right)$.

Embora existam muitos estados de oxidação do $\mathrm{Cr}$ na natureza, apenas as formas trivalente (III) e hexavalente (VI) são consideradas de importância biológica. Em ambientes aquáticos, o $\mathrm{Cr}(\mathrm{VI})$ está presente predominantemente na forma solúvel, que pode ser estável o suficiente para sofrer o transporte. No entanto, o Cr (VI) eventualmente será convertido em $\mathrm{Cr}$ (III), por meio de espécies redutoras como substâncias orgânicas, sulfeto de hidrogênio, dióxido de enxofre, sulfato ferroso, metabissulfito de sódio, amônio e nitrito, sendo que a maior efetividade na redução é atingida em $\mathrm{pH} \leq 3,0$ (Yabe e Oliveira 1998; Kimbrough et al. 1999). Segundo Richard e Bourg (1991), mudanças nas propriedades físico-químicas ( $\mathrm{pH}, \mathrm{Eh}, \mathrm{O}_{2}$ dissolvido) de um ambiente aquático podem resultar em mudanças no equilíbrio $\mathrm{Cr}$ (III) - Cr (VI).

Segundo EPA, o sedimento é considerado moderadamente poluído em relação ao $\mathrm{Cr}$ para teores que variam de $25 \mathrm{mg}$ $\mathrm{kg}^{-1}$ a $70 \mathrm{mg} \mathrm{kg}^{-1}$. Nesse caso, todos os pontos de coleta de sedimentos estariam moderadamente poluídos em relação ao $\mathrm{Cr}$, a exceção do ponto 13 , cujos valores foram inferiores aos limites supracitados. Na Figura 2D é apresentado o gradiente de distribuição do Cr ao longo do Rio Aurá. Nota-se que também há um decréscimo dos teores de $\mathrm{Cr}$ em direção a 
jusante do rio, como observado em outros íons metálicos analisados.

Nos sedimentos de fundo do Rio Aurá, o Ni variou entre 14,00 $\mathrm{mg} \mathrm{kg}^{-1}$ e 46,90 $\mathrm{mg} \mathrm{kg}^{-1}$ (Figura 2E), com média de $31,55 \pm 7,66 \mathrm{mg} \mathrm{kg}^{-1}$. Observou-se que em todos os pontos de amostragem, as concentraçôes de Ni ficaram abaixo do valor citado por Bowen (1979), que é de $68 \mathrm{mg} \mathrm{kg}^{-1}$ para folhelho médio padrão. Embora o $\mathrm{Ni}$ seja mais abundante que o $\mathrm{Cu}$, $\mathrm{Pb}$ e $\mathrm{Zn}$, ele tem poucos depósitos os quais são formados por sulfetos, arsenitos e teluritos, sendo que o mineral fonte mais importante é a garnierita $\left[(\mathrm{Ni}, \mathrm{Mg})_{6} \mathrm{Si}_{4} \mathrm{O}_{10}(\mathrm{OH})_{8}\right]$ (Moore e Ramamoorthy 1984), um mineral silicatado magnesiano hidratado. O Ni mineral advém de dois tipos de depósitos; lateríticos e supérgenos, onde a garnierita é a principal fonte, seguida da pentlandita $\left[(\mathrm{Fe}, \mathrm{Ni}){ }_{9} \mathrm{~S}_{8}\right]$, millerita $[\mathrm{NiS}]$, nicolita [NiAs] e gersdorfita [NiAsS]. Em todos os casos, os depósitos estâo associados à suites rochosas máfico-ultramáficas.

$\mathrm{Na}$ definição de grau de poluição do sedimento pelo $\mathrm{Ni}$, segundo classificação da EPA, todos os pontos amostrados, a exceçáo dos pontos próximos a foz do rio (pontos 29 e 30), ficaram enquadrados como moderadamente poluídos. Já com relação aos limites para sedimentos de regiôes naturais não impactadas, estabelecidos por Forstner e Wittmann (1983) e Moore e Ramamoorthy (1984), todos os pontos de coleta permaneceram com teor de Ni 2,8 a 9,4 vezes superior ao limite de $5 \mathrm{mg} \mathrm{kg}^{-1}$.

Os teores de $\mathrm{Cu}$ oscilaram ente $10,50 \mathrm{mg} \mathrm{kg}^{-1}$ e 28,80 $\mathrm{mg} \mathrm{kg}{ }^{-1}$ (Figura 2F) e média de 19,57 $\pm 4,52 \mathrm{mg} \mathrm{kg}^{-1}$, permanecendo sempre abaixo do valor citado por Bowen (1979) de $39 \mathrm{mg} \mathrm{kg}^{-1}$ para folhelho médio padrão. $\mathrm{Na}$ comparação com outros trabalhos da região, os teores de $\mathrm{Cu}$ do Rio Aurá permaneceram próximos aos obtidos por Siqueira et al. (2005) no canal do Uma (média $15,9 \mathrm{mg} \mathrm{kg}^{-1}$ ) e abaixo dos teores médios encontrados por Mendes e Berredo (2003) no Rio São Joaquim (média $58,43 \mathrm{mg} \mathrm{kg}^{-1}$ ). $\mathrm{O} \mathrm{Cu}$ pode estar presente no sedimento como precipitado insolúvel (por ex. hidróxido, fosfato ou sulfeto) ou adsorvido ao material particulado (Moore e Ramamoorthy 1984), especialmente na presença de argilominerais. Pela classificação do grau de poluição do sedimento pelo $\mathrm{Cu}$ da EPA, os sedimentos dos pontos $6,14,18,22$ e 28 seriam enquadrados como moderadamente poluídos, por estarem dentro do intervalo de 25 a $50 \mathrm{mg} \mathrm{kg}^{-1}$. Já comparando os resultados desta pesquisa com os limites estabelecidos por Forstner e Wittmann (1983) e Moore e Ramamoorthy (1984) para sedimentos de regióes não impactadas, tem-se que os teores encontrados no Rio Aurá chegaram a 98 vezes o limite de $0,2 \mathrm{mg} \mathrm{kg}^{-1}$ de $\mathrm{Cu}$, podendo dessa maneira, serem considerados como sedimentos extremamente poluídos por esse metal.

A análise do perfil vertical do oxigênio dissolvido permitiu observar que a componente oxidação predominou, na maior parte do tempo, à componente redução dos elementos Fe/ Mn no hipolímnio do Rio Aurá. A mistura de óxidos de Fe com aluminossilicatos facilita a imobilizaçáo de metais, especialmente em áreas contaminadas (Aguiar et al. 2002; Zhang et al. 2003). Os resultados demonstraram que o fluxo de corrente do rio, sobretudo durante as fases de águas altas, estabeleceu uma condição de oxigenação das camadas de água mais profundas, garantindo a formação de óxidos metálicos que, na forma hidratada, passaram a precipitar sob tais condiçóes, estimulados pelo $\mathrm{pH}>6,0$, elevando as concentraçôes dos elementos metálicos no compartimento sedimento (Figura 3). Esse fenômeno permanece inalterado enquanto existir uma camada oxidativa limite entre os compartimentos água e sedimento. A condição oxidativa ocorreu ainda que o trecho mais elevado da bacia sofra tanto influência direta como indireta do lixão/aterro sanitário, e da poluição por descarte de esgotos misturados a águas pluviais oriundas da urbanização irregular. Entende-se como influência direta o recebimento de efluentes sanitários e chorume náo tratados transportados pelos igarapés, e como influência indireta a eutrofização do ecossistema aquático decorrente da poluição ambiental. Nesse contexto, a carga orgânica transportada para o corpo receptor não foi suficiente para reduzir o teor de oxigênio a teores próximos da anoxia, visto haver, na maior parte do tempo, o fluxo de corrente mencionado anteriormente. Nos períodos do ciclo hidrológico de águas baixas (seca), entretanto, pode haver ruptura do processo de precipitaçáo metálica, em virtude de uma momentânea anoxia do hipolímnio. Entende-se assim, que o ciclo hidrológico na Amazônia tem forte influencia na variaçáo do potencial redox no hipolímnio e, dessa forma, influencia na taxa de precipitação e liberação de íons metálicos para e do sedimento. Talvez este fato justifique a heterogeneidade dos teores de íons metálicos encontrados ao longo curso do Rio Aurá.

As fontes de metais para os ecossistemas aquáticos em geral podem ser naturais (intemperismo das rochas e solos) ou antropogênicas, neste caso destacando-se as atividades mineradoras; águas de drenagem; óleo combustível de embarcaçôes; resíduos de indústrias de tintas, fertilizantes,

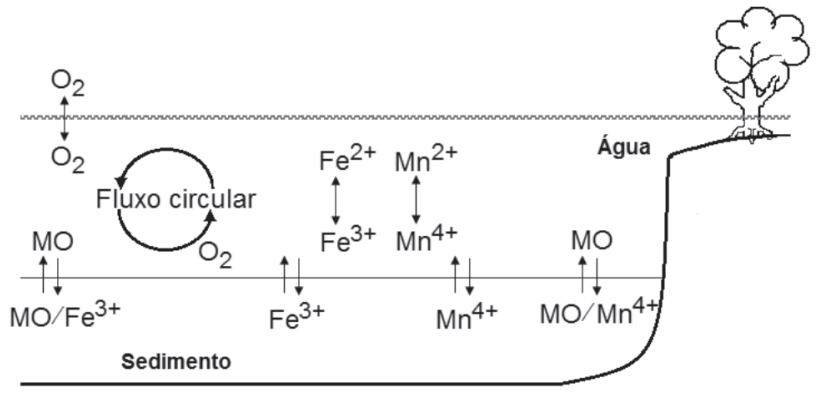

Figura 3- Modelo de fluxo dos íons metálicos Fe e Mn entre os compartimentos água e sedimento em função do fluxo de oxigênio no hipolímnio. 
têxtil, pesticidas e farmacêuticas; efluentes domésticos; escoamento de área agrícola e chuva ácida (Klavins et al. 2000; Yu et al. 2001; Ansari et al. 2004). Deve-se entender que mesmo complexados e precipitados ao sedimento, os metais continuam a apresentar forte potencial poluente e contaminante para a coluna de água (Klavins et al. 2000; Singh 2005), visto que o compartimento sedimento pode funcionar como 'pool' de substâncias tóxicas introduzidas no ambiente aquático, com potencial para liberar para coluna de água, a qualquer momento, compostos químicos extremamente tóxicos acumulados por décadas ou centenas de anos, que passarão a ser incorporados à cadeia trófica.

$\mathrm{O}$ teor de $\mathrm{C}_{\text {org }}$ determinado nas amostras de sedimentos variou entre $1,08 \%$ e $3,02 \%$ com média $2,06 \pm 0,50 \%$ (Figura 4A), sendo que as maiores concentraçóes ocorreram no setor mais lodoso e com menores processos energéticos, o que pode ser indicativo do papel dos sedimentos no transporte de nutrientes. $\mathrm{O}$ padrão de distribuiçấo do $\mathrm{C}_{\text {org }}$ foi de maiores concentraçóes a montante da bacia e menores próximo a foz no Rio Guamá (Figura 1). Já as concentraçóes de $\mathrm{N}_{\text {org }}$ permaneceram entre $0,02 \%$ e $0,17 \%$ com média $0,12 \pm 0,03 \%$ (Figura 4B), muito abaixo do que geralmente é reportado para áreas parcialmente urbanizadas. As formas orgânicas de carbono e nitrogênio variaram distintamente ao longo da área de estudo tendo, por conseguinte, significaçóes diferenciadas no que tange aos valores de referência estipulados para determinar a qualidade ambiental do compartimento sedimento (CCME 2002). Dessa forma, o $\mathrm{C}_{\text {org }}$ ficou 6,7 vezes maior do que o valor de referência médio de $0,3 \%$, geralmente encontrado em ambientes não impactados, enquanto que o $\mathrm{N}_{\text {org }}$ ficou abaixo do valor médio de $0,29 \%$

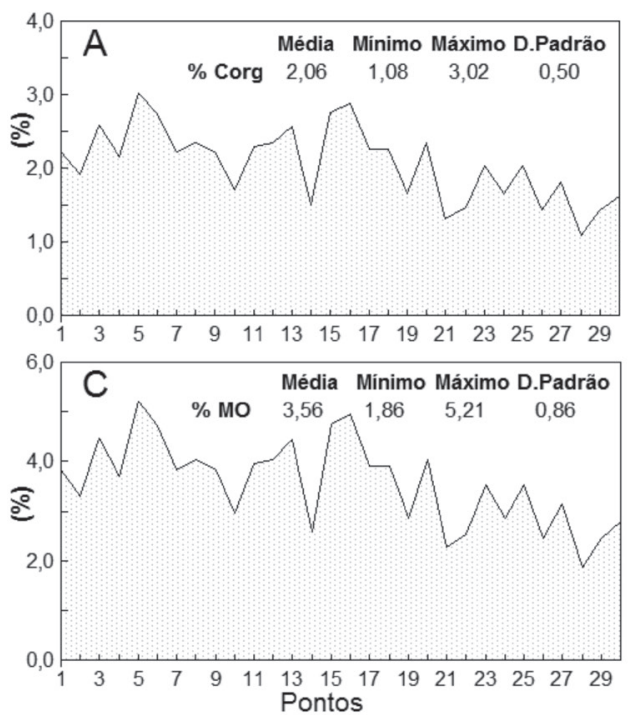

para a mesma condição. É possível que as concentraçóes mais significativas de carbono e nitrogênio orgânicos no Rio Aurá tenham origem tanto natural como antrópica. Como a concentraçáo de $\mathrm{MO}$ no sedimento de fundo é decorrente da produção, transporte e decomposição, os resultados obtidos para o rio Aurá provavelmente sejam influenciados pelo aumento geral da poluição de caráter local (fontes pontuais), especialmente devido aos despejos provenientes do lixão/ aterro sanitário do Aurá, localizado a montante da bacia (Figura 1), como sugeriu Morales (2002). Os conteúdos de $\mathrm{MO}$ presentes nos sedimentos apresentaram a mesma tendência descrita para $\mathrm{C}_{\text {org }}$, oscilando entre 1,86\% e 5,21\% e média de 3,56 $\pm 0,86 \%$ (Figura 4C). Observaram-se teores significativos de $\mathrm{MO}$ em ambientes de baixa energia (a montante do sistema), com predominância a sedimentos finos, o que é normal, uma vez que esses são locais típicos de sedimentação. De certa forma, a baixa velocidade das correntes de maré, que ocorrem geralmente em regióes abrigadas, ocasiona o acúmulo de grande quantidade de $\mathrm{MO}$ e partículas finas no ambiente sedimentar. A quantidade de carbono e matéria orgânica nos sedimentos depende de dois principais fatores: deposição e decomposição. A deposição está diretamente associada à produção biológica, porém é limitada pelos aspectos geomorfológicos, como: profundidade, hidrodinâmica local e diâmetro das partículas, entre outros. Já a decomposição depende do teor de oxigênio dissolvido disponível, da presença de organismos decompositores e da natureza do material inorgânico. Além disso, outros fatores físicos e químicos também têm influência sobre o processo, incluindo estratificação térmica (física) e química; dinâmica de massas de água e potencial de oxi-redução.

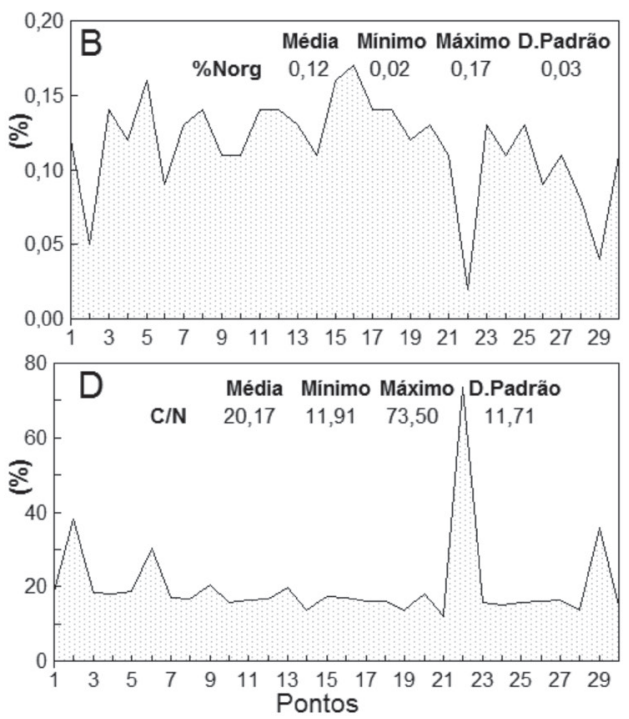

Figura 4- Gradiente de distribuição espaço-temporal do A) carbono e B) nitrogênio orgânicos, C) matéria orgânica e D) razão C/N (valores médios) para os sedimentos do Rio Aurá, entre 2008 e 2010. 
O carbono e o nitrogênio são os dois principais componentes da matéria orgânica, sendo que o conteúdo de $\mathrm{C}_{\text {org }}$ presente nos sedimentos depende, entre outros, da taxa de degradação microbiana, da produtividade da coluna de água e das entradas de material alóctone provenientes dos solos marginais. Dessa forma, a relação $\mathrm{C} / \mathrm{N}$ existente nos ambientes aquáticos poderá indicar o conteúdo e a via de fluxo de cada macronutriente nos diversos compartimentos do ecossistema. As razóes $\mathrm{C} / \mathrm{N}$ obtidas nesta pesquisa tiveram alta variação de 11,91 a 73,50 , com média de $20,17 \pm 11,71$ (Figura 4D), o que poderia indicar fontes ou vias diferenciadas de contribuição de $\mathrm{MO}$ para o compartimento sedimentar. De maneira geral, as razôes $\mathrm{C} / \mathrm{N}$ determinadas refletiram certa estabilidade da MO preservada nas amostras coletadas, com padrão $\mathrm{C} / \mathrm{N}<20$, excluindo os pontos $2,6,22$ e 29, que apresentaram razóes $\mathrm{C} / \mathrm{N}$ elevadas. Nestes pontos, pode estar havendo influência de apreciáveis quantidades de detritos orgânicos de origem vegetal residual, provenientes de áreas que estão sendo desmatadas. Altos teores de matéria orgânica de origem vegetal residual têm as mais baixas taxas de nitrogênio e assim a razáo C/N passa a ser elevada. Saito et al. (1989) sugerem que razóes $\mathrm{C} / \mathrm{N}$ da ordem de 20 representariam MO de origem continental, e valores entre 5 e 12 contribuiçôes provenientes, além das plantas terrestres, de material orgânico autóctone do plâncton. Faganelli et al. (1988) reforçam a idéia de que altas taxas de $\mathrm{C} / \mathrm{N}$ em sedimentos, especialmente marinhos, podem indicar uma contribuição mais significativa de matéria orgânica terrígena. De fato, acredita-se que razōes $\mathrm{C} / \mathrm{N}$ elevadas podem representar grande influência terrígena para matéria orgânica nos sedimentos, como tem ocorrido na região de estudo em determinados trechos da bacia, tanto a montante quanto a jusante, cuja atividade antrópica resulta na produção de efluentes não tratados que escoam para o rio.

Para avaliar as mudanças nas concentraçôes dos íons metálicos estudados nos sedimentos de fundo do Rio Aurá, foi calculado o fator de enriquecimento (FE). Com o intuito de diminuir os efeitos mineralógicos e de tamanho de grão, foi feita à normalizaçáo dos dados obtidos utilizando-se o Al como elemento conservativo (Bowen 1979; Woitke et al. 2003; Selvaraj et al. 2004). Vale ressaltar, que devido às suas características intrínsecas, o fator de enriquecimento representa somente a acumulaçáo de metais no ambiente sedimentar próximo, não proporcionando, assim, informaçôes sobre a forma (fração mobilizável) que os metais se encontram associados aos sedimentos de fundo.

A Tabela 1 mostra os fatores de enriquecimentos (FE) determinados para os íons metálicos estudados. De maneira geral, os FE determinados indicaram a existência de fatores relativamente baixos $(\cong 1)$, sugerindo assim que não houve enriquecimento ou depleçáo dos íons metálicos nos sedimentos de fundo amostrado no ambiente sedimentar próximo. Entretanto, em alguns pontos verificaram-se FE $>1$ indicando aporte de material para o sistema fluvial. Dessa maneira, pode-se aventar a hipótese de que a pluma de chorume, proveniente do lixão/aterro sanitário do Aurá, esteja contribuindo, de certa forma, com o enriquecimento dos íons metálicos em determinados pontos do Rio Aurá. Estudos

Tabela 1- Fatores de enriquecimentos calculados a partir da equação 2, descrita por Woitke et al. (2003) e Selvaraj et al. (2004), para 0s íons metálicos determinados na bacia do Rio Aurá.

\begin{tabular}{|c|c|c|c|c|c|c|c|c|c|c|c|}
\hline Pontos de coleta & $\mathrm{Fe}$ & $\mathrm{Mn}$ & $\mathrm{Cr}$ & $\mathrm{Ni}$ & $\mathrm{Cu}$ & Pontos de coleta & $\mathrm{Fe}$ & $\mathrm{Mn}$ & $\mathrm{Cr}$ & $\mathrm{Ni}$ & $\mathrm{Cu}$ \\
\hline 1 & 0,9 & 0,5 & 1,1 & 0,9 & 0,9 & 16 & 1,0 & 0,8 & 0,9 & 0,9 & 1,0 \\
\hline 2 & 1,3 & 0,8 & 1,2 & 0,9 & 0,9 & 17 & 1,0 & 0,5 & 1,0 & 1,1 & 1,1 \\
\hline 3 & 0,9 & 0,7 & 1,1 & 0,9 & 0,8 & 18 & 1,2 & 0,5 & 1,0 & 1,1 & 1,2 \\
\hline 4 & 1,0 & 0,4 & 1,1 & 0,9 & 1,0 & 19 & 1,0 & 0,5 & 1,0 & 0,9 & 0,9 \\
\hline 5 & 1,0 & 0,7 & 1,0 & 1,0 & 1,0 & 20 & 1,0 & 0,6 & 1,0 & 0,9 & 1,0 \\
\hline 6 & 0,9 & 0,6 & 1,1 & 0,9 & 1,0 & 21 & 1,0 & 0,6 & 1,0 & 0,8 & 0,9 \\
\hline 7 & 1,0 & 0,6 & 1,1 & 1,0 & 1,0 & 22 & 1,0 & 0,6 & 1,0 & 0,9 & 1,1 \\
\hline 8 & 1,0 & 0,7 & 1,0 & 0,8 & 0,9 & 23 & 1,2 & 0,8 & 0,9 & 1,0 & 1,1 \\
\hline 9 & 0,9 & 0,5 & 1,1 & 0,9 & 0,9 & 24 & 1,0 & 1,0 & 1,0 & 0,8 & 0,9 \\
\hline 10 & 1,1 & 0,6 & 1,1 & 0,8 & 0,9 & 25 & 1,1 & 1,1 & 1,0 & 0,9 & 0,9 \\
\hline 11 & 1,2 & 0,7 & 1,1 & 0,8 & 0,8 & 26 & 1,2 & 0,7 & 1,1 & 0,8 & 1,0 \\
\hline 12 & 1,2 & 0,7 & 1,1 & 0,9 & 1,0 & 27 & 1,1 & 0,6 & 1,0 & 0,7 & 0,9 \\
\hline 13 & 1,0 & 0,7 & 0,5 & 0,9 & 1,0 & 28 & 1,1 & 0,7 & 1,0 & 0,1 & 1,8 \\
\hline 14 & 1,0 & 0,5 & 0,6 & 0,9 & 1,1 & 29 & 1,2 & 1,5 & 0,9 & 0,7 & 1,0 \\
\hline 15 & 1,0 & 0,7 & 1,0 & 1,0 & 0,9 & 30 & 1,2 & 1,3 & 1,0 & 0,7 & 0,9 \\
\hline
\end{tabular}

Negrito $=$ Fator de enriquecimento $>1$ 
desenvolvidos por Morales (2002) e Bahia et al. (2004), na área da bacia do Rio Aurá e cercanias, revelaram haver grande possibilidade de contaminação dos igarapés que compõem a malha hídrica local pelo chorume produzido e escoado do aterro sanitário.

O resultado da análise de variância é apresentado na Tabela 2. Levou-se em consideração a análise do elemento metálico alumínio, por este ter apresentado um comportamento mais conservativo no sistema. Das correlaçóes obtidas os melhores desempenhos foram obtidos entre Al-Fe e $\mathrm{Al}-\mathrm{Ni}$, com $\mathrm{r}>$ 0,9000 e $p<0,000001$, cujas tendências de distribuição espaço-temporal se mostraram bastante semelhantes. Além disso, os três metais apresentam número de eletronegatividade próximos, estado de oxidação +3 e, grande afinidade por ânions, com complexação em associação a $\mathrm{MO}$ e argilominerais. Tais correlaçôes confirmaram as associaçôes entre os íons metálicos com oxihidróxidos hidratados de $\mathrm{Al}$ e $\mathrm{Fe}$ apontadas anteriormente. Os íons metálicos podem coprecipitar na forma de colóides ou adsorver em oxihidróxidos hidratados de metais mais abundantes como Al, $\mathrm{Fe}$ ou ainda $\mathrm{Mn}$. Isso dependerá muito do $\mathrm{pH}$ do meio, que pode provocar processos de arraste por oclusão ou adsorção dos íons. De acordo com Yabe e Oliveira (1998), a partir de $\mathrm{pH} \geq 2,2$ começa ocorrer precipitação do Fe para o sedimento, que é potencializado para os outros metais acima de $\mathrm{pH}=$ 4,5. O Al apresenta muito boa adsorção em argilominerais do tipo caulinita, illita e esmectita, que neste caso são muito comuns nos sistemas fluviais amazônicos. Além do mais, o $\mathrm{Al}$ atua como componente-traço de minerais primários resistatos de rochas de áreas-fonte intemperisadas, comumente transportados pelos rios de águas brancas da regiâo. A condiçẫo alóctone não estabelece um limite espacial para o transporte,

Tabela 2- Análise de variância do alumínio determinado nos sedimentos da bacia do Rio Aurá no período de 2008 a 2010 e usado como fator de referência no ambiente de estudo.

\begin{tabular}{cccccc}
\hline Correlação & $\mathrm{r}$ & $\mathrm{R}^{2}$ & $F$ & $\mathrm{n}$ & $p$ \\
\hline Al x Fe & 0,9135 & 0,8344 & 47,1490 & 90 & $<0,000001$ \\
\hline Al x Mn & 0,1649 & 0,2721 & 0,7831 & 90 & 0,383735 \\
Al x Cr & 0,7329 & 0,5371 & 18,7192 & 90 & 0,000174 \\
\hline Al x Ni & 0,9096 & 0,8274 & 48,5932 & 90 & $<0,000001$ \\
Al x Cu & 0,7765 & 0,6030 & 23,6269 & 90 & 0,000041 \\
\hline Al x C org & 0,4642 & 0,2155 & 7,6930 & 90 & 0,009754 \\
Al x N org & 0,2407 & 0,5792 & 1,7215 & 90 & 0,200148 \\
\hline Al x M0 & 0,4651 & 0,2163 & 7,7299 & 90 & 0,009600 \\
\hline
\end{tabular}

$r=$ coeficiente de correlação de Pearson; $R^{2}=$ coeficiente linear; $F=$ teste de Fisher; $\mathrm{n}=$ tamanho da amostra; $p=$ índice de distribuição binomial. sendo que se enquadram neste item os quartzos e quartzitos, que podem atravessar milhares de quilômetros da área-fonte à bacia, ou argilitos e siltitos oriundos dos solos marginais. Já a condição autóctone é bem mais restrita espacialmente falando, limitando-se a processos químicos e/ou biológicos de fornecimento de minerais a partir do próprio ambiente fluvial.

A partir da análise geoquímica e aplicando-se a Análise de Componentes Principais (PCA) buscou-se elaborar um fluxograma para classificaçáo geral dos materiais sedimentares (Figura 5), em função da origem dos componentes. Do ponto de vista estatístico, a PCA de duas componentes explicou mais de $88 \%$ do comportamento de distribuição dos íons metálicos ao longo do Rio Aurá, sendo que a componente 1 evidenciou as fontes orgânicas e os sedimentos argilosos contendo metais transportados em associação a estas, como é o caso do $\mathrm{Fe}$ e $\mathrm{Al}$, e foi responsável por $52 \%$ da explicação. A componente 2 explicou $36 \%$ do comportamento de distribuição, evidenciando as fontes quanto a origem autóctone e alóctone. Os resultados demonstraram que o transporte mecânico tem como característica, nos corpos de água branca, conduzir alta carga de sedimentos arenoargilosos e argilo-arenosos ricos em $\mathrm{Fe}$ e $\mathrm{Al}$, além do que, as fontes terrígenas fora da bacia sedimentar contribuem além do Fe com Mn. Os depósitos terrígenos ou extraclásticos correspondem a fragmentos retirados mecanicamente dos solos marginais e redepositados em um curto espaço de tempo nos sedimentos da bacia. Neste caso, a distância de transporte limita-se às fronteiras da bacia ou no próprio sistema fluvial, e é restrita ao máximo transporte que o extraclasto e/ou o intraclasto podem permanecer em suspensão. Já os compostos orgânicos $\left(\mathrm{MO}, \mathrm{C}_{\mathrm{org}}\right.$ e $\mathrm{N}_{\mathrm{org}}$ ) sofreram influência dos processos químicos e biológicos (decomposição aeróbia e anaeróbia) durante a formação dos clastos sendo, portanto, caracterizados como fraçóes sedimentares alobioquímicas. $\mathrm{Na}$ mesma condição, o Cr passa por diversos estados de oxirredução no sistema fluvial, sendo a forma hexavalente predominante no ambiente aeróbio, e apenas em condiçôes específicas de

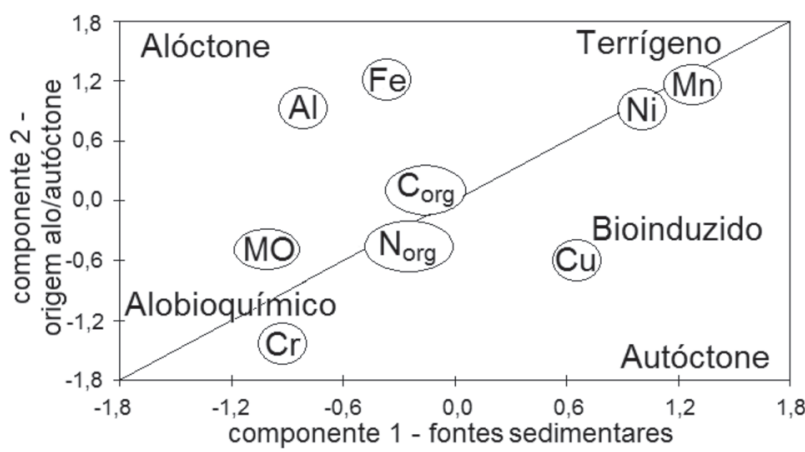

Figura 5- Análise de Componentes Principais com proposta de classificação geral dos materiais sedimentares a partir da caracterização do transporte no Rio Aurá. 
baixas concentraçóes de oxigênio dissolvido, durante as fases de seca, alterna-se em predominância com a forma trivalente. Segundo a análise, os elementos metálicos $\mathrm{Cu}$ e $\mathrm{Ni}$ são predominantemente fornecidos ao compartimento sedimento por fontes autóctones, sendo que neste caso o metabolismo vegetal induz a precipitação química de tais elementos. Do ponto de vista físico, o transporte sedimentar é resultado das forças atuantes no sistema fluvial, destacando a viscosidade e a densidade, que são diretamente dependentes da temperatura da água e a velocidade de corrente, que está relacionada com a geomorfologia da região.

\section{CONCLUSÃO}

Com relação aos gradientes de distribuição dos íons metálicos avaliados, conclui-se que, a exceção do Mn, ocorreu um decréscimo nos teores desses em direçáo a foz do Rio Aurá, sugerindo a não formação de estoques metálicos nos sedimentos ao longo da bacia. Os sedimentos superficiais coletados na bacia revelaram um padrão granulométrico dominado pela classe textural areno-lamoso, contendo argilominerais como caulinita, illita e esmectita, que favoreceram a adsorção metálica no sedimento de fundo. Além disso, os sedimentos podem estar sendo adsorvidos aos óxidos hidratados e hidróxidos de metais mais abundantes na regiấo como o Al e Fe. Em decorrência dessa adsorção, acredita-se estar havendo uma baixa biodisponibilidade de metais para a cadeia trófica local.

Analisando os fatores de enriquecimentos e o critério de qualidade ambiental da EPA utilizado no trabalho, concluiu-se que principalmente os íons metálicos $\mathrm{Al}, \mathrm{Cr}, \mathrm{Fe}$ e Ni estão sob influência da pluma de chorume do lixão/ aterro sanitário do Aurá, existente na cabeceira da bacia. Dessa forma, práticas de preservação ambiental devem ser aplicadas à bacia, especialmente no que se refere à contenção da urbanizaçáo descontrolada, contençáo e tratamento do chorume oriundo do aterro sanitário, recuperação da mata marginal em áreas desmatadas, e implantação de um programa de monitoramento contínuo dos teores metálicos na RMB.

\section{AGRADECIMENTOS}

Ao Conselho Nacional de Desenvolvimento Científico e Tecnológico de Pesquisa - CNPq pela concessão de bolsa de iniciação científica a Ieda Soffiatti, do Laboratório de Absorção Atômica do MPEG; a Faculdade de Química da UFPA, pela disponibilidade do Laboratório de Química para as análises; a PROPESP pelo financiamento do projeto.

\section{BIBLIOGRAFIA CITADA}

Aguiar, M.R.M.P.; Novaes, A.C.; Guarino, A.W.S. 2002. Remoção de metais pesados de efluentes industriais por aluminos-silicatos. Quimica Nova, 25: 1145-1154.

Aguiar, S.A. 2000. Degradação sócia ambiental: um estudo sobre a população residente a proximidade da foz do igarapé Tucunduba (Belém/Pará). Trabalho de Conclusão de Curso de Especialização em Educação Ambiental, Núcleo de Meio Ambiente, UFPA, Belém, PA. 49 pp.

Ansari, T.M.; Marr, I.L.; Tariq, N. 2004. Heavy metals in marine pollution perspective - A Mini review. Journal of Applied Sciences, 4(1): 1-20.

APHA/AWWA/WEF. 2005. Standard methods for examination of water and wastewater. American Public Health Association, American Water Works Association and Water Environment Federation. 21st ed., Washington. 4358 pp.

Aprile, F.M.; Bianchini Jr., I. 2003. Adequação metodológica para determinaçáo do nitrogênio orgânico total em macrófitas aquáticas e sedimentos. Revista Brasileira de Biociências, 8: 49-56.

Bahia,V.E.; Luiz, J.G.; Fenzl, N. 2004. Influência do depósito sanitário metropolitano de Belém (Aurá) sobre as águas subterrâneas da área. Revista Águas Subterrâneas, 18: 89-102.

Bowen, H.J.M. 1979. Environmental chemistry of the elements. London Academic Press, London. 273 pp.

Byers, S.; Mills, E.; Stewart, P. 1978. Comparison of methods of determining organic carbon in marine sediments, with suggestions for a standard method. Hydrobiologia, 58: 43-47.

CCME - Canadian Council of Ministers of the Environment. 2002. Canadian sediment quality guidelines for the protection of aquactic life: summary tables. Winnipeg, CA. (http://www. ccme.ca/assets/pdf/sedqg_summary_table.pdf) Acesso em 21/12/2010.

Embrapa - Empresa Brasileira de Pesquisa Agropecuária. 1999. Centro Nacional de Pesquisa de Solos. Sistema brasileiro de classificação de solos. Embrapa Produção da Informação, Rio de Janeiro. 412 pp.

Faganelli, J.; Malej, A.; Pezdic, J.; Malacic, V. 1988. C:N:P ratios and stable $\mathrm{C}$ isotopic ratios as indicator of sources of organic matter in the Gulf of Trieste (northern Adriatic). Oceanologia Acta, 11: 377-382.

Ferreira, M.; Costa, T. 2006. Natural aggregate potential and associated environmental problems in the Aurá portion, Belém metropolitan region (BMR), State of Pará, Brazil. The Geological Society of London - IAEG, 187: 1-13.

Förstner, U.; Wittmann, G.T.W. 1983. Metal Pollution in the Aquatic Environment. Springer-Verlag, Berlin. 486 pp.

Kimbrough, D.E.; Cohen, Y.; Winer, A.M.; Creelman, L.; Mabuni, C. 1999. A critical assessment of chromium in the environment. Critical Reviews in Environmental Science and Technology, 29(1): $1-46$. 
Klavins, M.; Briede, A.; Rodinov, V.; Kokorite, I.; Parele, E.; Klavina, I. 2000. Heavy metals in river of Lativa. Science of the Total Environment, 262: 175-183.

Mendes, A.C.; Berredo, J.F. 2003. Metais totais em sedimentos de fundo do canal São Joaquim e igarapé do Burrinho-Belém/ PA: Conflitos ambientais e legislacionais. Anais do IX Congresso Brasileiro de Geoquímica, Belém, PA. pp: 109-112.

Moore, J.W.; Ramamoorthy, S. 1984. Heavy metals in natural waters. Spinger-Verlag, Berlin. 268 pp.

Morales, G.P. 2002. Avaliação ambiental dos recursos hídricos, solos e sedimentos na área de abrangência do depósito de residuos sólidos do Aurá. Tese de Doutorado em Hidrogeoquímica, Centro de Geociências, UFPA, Belém, PA. 240 pp.

Richard, F.C.; Bourg, A.C.M. 1991. Aqueous geochemistry of chromium: a review. Water Research, 25(7): 807-816.

Saito, Y.; Nishimura, A.; Matsumoto, E. 1989. Transgressive sand sheet covering the shelf and upper slope off Sendai, Northeast Japan. Marine Geology, 89: 245-258.

Selvaraj, K.; Ram Mohan, V.; Szefer, P. 2004. Evaluation of metal contamination in coastal sediments of the Bay of Bengal, India: geochemical and statistical approaches. Marine Pollution Bulletin, 49: 174-185.

Signh, K.P.; Mohan, D.; Signh, V.K.; Malik, A. 2005. Studies on distribution and fractionation of heavy metals in Gomti river sediment - a tributary of the Ganges, India. Journal of Hydrology, XX:1-14.

Siqueira,G.W.; Grana, R.J. de A.; Gama, L. de L. 2005. Aspectos geoquímicos na avaliação ambiental dos sedimentos superficiais provenientes da bacia hidrográfica do Una - Belém-PA. Revista do Lesan, 3(1,2): 120-137.
Thomas, R.L. 1987. A protocol for the selection of process-oriented remedial options to control in situ sediments contaminants. Ecological effects of in situ sediments contaminants. Hydrobiology, 149: 247-258.

Wedepohl, K.H. 1995. The composition of the continental crust. Geochimica et Cosmochimica Acta, 59(7): 1277-1232.

Woitke, P.; Wellmitz, J.; Helm, D.; Kube, P.; Lepom, P.; Litheraty, P. 2003. Analysis and assessment of heavy metal pollution in suspended solids and sediments of the river Danube. Chemosphere, 51: 633-642.

Yabe, M.J.S.; de Oliveira, E. 1998. Metais pesados em águas superficiais como estratégia de caracterização de bacias hidrográficas. Quimica Nova, 21(5): 551-556.

Yu, K.Y.; Tasi, L.J.; Chen, S.H.; HO, S.T. 2001. Chemical binding of heavy metals in anoxic river sediments. Water Research, 35(7): 4086-4094.

Yun, S.T.; Choi, B.Y.; Lee, P.K. 2000. Distribution of heavy metals $(\mathrm{Cr}, \mathrm{Cu}, \mathrm{Zn}, \mathrm{Pb}, \mathrm{Cd}$, As) in roadside sediments, Seoul metropolitan city, Korea. Environment Technology, 21:989-1000.

Zhang, Y.; Yang, M.; Huang, X. 2003. Arsenic(V) removal with a Ce(IV)-doped iron oxide adsorbent. Chemosphere, 51: 945-952.

Recebido em: 06-09-2011

Aceito em: 18-03-2012 
